\title{
GIS-Based Quantitative Study of Soil Erosion in Miyun County, Beijing
}

\author{
Jing Zhao ${ }^{1, ~ a ~, ~ J i n g ~ Z h a n g ~}{ }^{2, ~ b *}$, Binbin Guo ${ }^{3, c}$ \\ ${ }^{1,2}$ The Key Lab of Resource Environment \& GIS of Beijing, Capital Normal University, Beijing, \\ China, 100048 \\ agisjing@126.com ${ }^{\mathrm{b}}$ corresponding author: maggie2008zj@yahoo.com couobinbinbin@qq.com
}

\begin{abstract}
Keywords: Quantitative study of soil erosion; USLE; GIS; RS
ABSTRACT.Soil erosion by water is a serious problem all over the world. In China, about 1790000 $\mathrm{km}^{2}$ of land suffers from water erosion, which accounts for $18.3 \%$ of China's total area. Based on RS and GIS methods, this paper taking Miyun County as the study area, with 2011 rainfall data, Landsat TM images, ASTER GDEM digital elevation data, soil type and other information for the data source. Using USLE model assess Miyun County soil erosion in 2011, analysis of spatial distribution characteristics of soil erosion in Miyun County, as well as quantitative study of the relationship between the intensity of soil erosion and slope. The results showed that, more than half of the area is under a mired erosion, soil erosion is more serious condition in Miyun County. The investigation indicated that it is the characteristic of terrain, soil type, and climate of Miyun County is easy to form soil erosion. The useful recommendations on sustainable ecological restoration plan were provided to solve this issue.
\end{abstract}

\section{INTRODUCTION}

Soil erosion refers to the role of soil by water, wind, freezing and thawing, or some other force of gravity, under the influence of anthropogenic factors and natural factors are destroyed, erosion, transport and deposition processes. With the continuous development of society, and the worsening of ecological environment, require the origin, process, distribution of soil erosion and the present situation and development trend has a more comprehensive understanding. A qualitative description of soil erosion cannot meet this requirement, so needs to study soil erosion quantitatively.

In 1959, Wischmeier and Smith ${ }^{[1]}$ put forward the universal soil loss equation USLE. The universal soil loss equation on soil erosion factors are divided into the rainfall erosivity factor $\mathrm{R}$, soil erodibility factor $\mathrm{K}$, the factor of slope length and slope, vegetation cover and management factor $\mathrm{C}$, conservation supporting practice factor P. In 1997 US Soil Conservation Service (SCS) has launched a revised version of USLE RUSLE ${ }^{[2]}$, for USLE made significant improvements. In recent years, with the development of computer technology and the application of GIS and related technology, for the quantitative study of soil erosion pioneered the new research methods and fields, and achieved a large number of achievement.

\section{STUDY AREA AND METHODOLOGY}

\section{Study area}

Miyun County located in the northeast of Beijing, is plain and mountainous border region. Miyun County, a total area of 2229.45 square kilometers, accounting for $13 \%$ of the Beijing total area, is the largest district and county of Beijing. Miyun County surrounded on three sides by mountains, and Miyun Reservoir is the largest artificial lake in north China.

Miyun County average annual rainfall is 661.3 millimeters, annual average temperature is 10.8 degrees, and it is an important area of drinking water source and the ecological conservation development area in the capital. Miyun County mainly terrain is mountains and hills, plains only distributed in the southwest of area. Mountains accounted for $46.7 \%$ of total area, hills accounted for $36.6 \%$; Plain $(8.3 \%)$, in the middle of the Miyun Reservoir accounts for about $8.4 \%$. For the land use, cultivated land is mainly distributed in the southwest, mountains is given priority to with forest land use, the soil type is mainly brown soil, brown soil, Chao soil. 
Methodology

Universal soil loss equation (USLE) is erosion mathematical model that shows the quantitative relationship between the sloping fields' soil erosion and its main influenced factors. USLE used to calculate the average annual soil loss caused by the surface corrosion under the certain cultivation methods and management system. The expression is:

$$
\mathrm{A}=\mathrm{R} \cdot \mathrm{K} \cdot \mathrm{L} \cdot \mathrm{S} \cdot \mathrm{C} \cdot \mathrm{P}
$$

where $\mathrm{A}$ is the average value of unit area per year; $\mathrm{R}$ is the factor of rainfall; $\mathrm{K}$ is the factor of erodibility; $\mathrm{L}$ is the length of slope; $\mathrm{S}$ is the slope steepness; $\mathrm{C}$ is the factor of vegetation and management and $\mathrm{P}$ is the factor of measure of water and soil conservation.

\section{Rainfall erosivity factor $R$}

Soil erosion caused by rainfall is the most direct external factors, power generated by the raindrops impact on soil particles, generate splash erosion, and once again lead to the occurrence of soil erosion. In the universal soil loss equation, rainfall erosivity factor is one of the most basic factor, it is a important evaluative index to quantitatively detect soil erosion for a region ${ }^{[3]}$.

\section{Soil erodibility factor $\mathbf{K}$}

Soil erodibility factor is an evaluation of the soil is separated erosivity, impact and handling ease of indicators. This paper main reference to Chinese scholars summed up the main soil types of $\mathrm{K}$ value $\mathrm{e}^{[4]}$. Topographic factors $L$ and $S$

Used in this study is a classic slope length factor formula Wischmeier and Smith proposed in 1978.

Slope factor mainly reflect the influence of slope soil erosion. S was estimated using method from the steep slope soil erosion research ${ }^{[5]}$.

Vegetation cover and management factor $\mathbf{C}$

Vegetation cover and management factor, referring to the characteristics of vegetation, such as the growing season, crop production system and vegetation types in the same soil slope and rainfall conditions, the characteristics of comprehensive effects of soil erosion, it also reflects the impact of human activities.

\section{Conservation supporting practice factor $\mathbf{P}$}

Conservation supporting practice factor represents the ratio between soil loss under the particular soil and water conservation measures and corresponding soil conservation measures are not the slope soil loss of farming land.

\section{RESULTS AND DISCUSSION}

\section{Results}

Previously, this paper discusses extraction method of each factor the universal soil loss equation in Miyun County, and the map of estimated annual soil erosion is shown in Fig.1. We can see the distribution of soil erosion. According to the soil erosion classification standard, classified the soil erosion modulus of Miyun Country.

The result shows that, $68.83 \%$ of the study area is under a mired erosion rate, while $29.47 \%$ of the area was found to be under a slight erosion rate. A moderate erosion rate was found on $1.89 \%$ of the study area, while around $0.01 \%$ of the area was under a high erosion rate. 


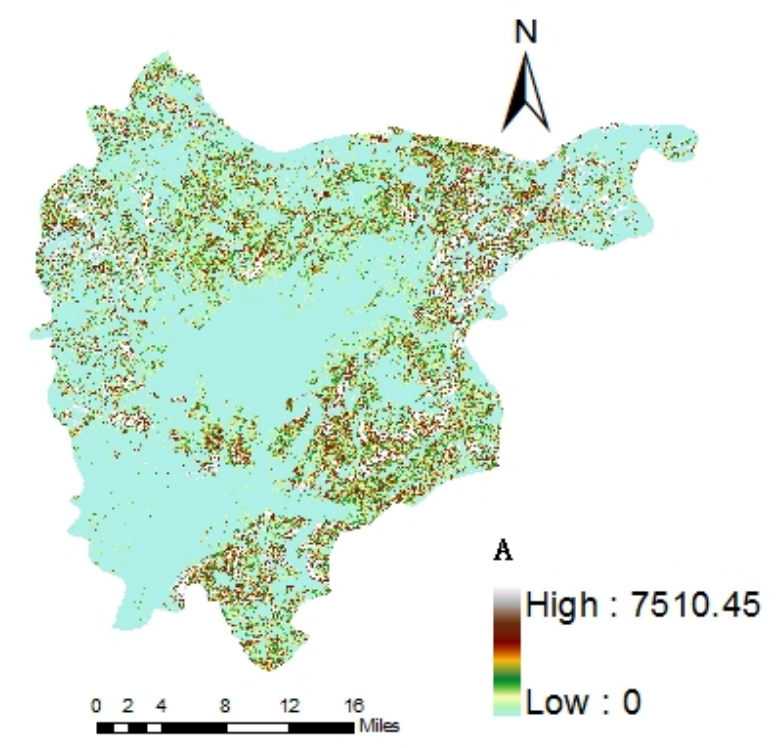

\section{Discussion}

Figure 1. Soil erosion modulus map of Miyun

Overall, the area of slight erosion and mild erosion accounting for $98.3 \%$ of the total land area. After analysis the main reasons can be drawn: Miyun County terrain surrounded by mountains on three sides, the characteristic of terrain is easy to form soil erosion; The soil type of Miyun County is mainly cinnamon soil, with greater soil erodibility, soil layer is thin, as well as Miyun Country is mainly mountainous area, and belongs to the monsoon climate, annual precipitation variability is large, easy to cause soil erosion; Irrational land use structure, in order to develop the economy, deforestation, cultivation on steep slopes, severely damaged the vegetation on mountains. Therefore, take soil and water conservation measures to control soil erosion in Miyun County is extremely urgent.

\section{CONCLUSIONS}

Based on USLE, RS, GIS, this study is an attempt to estimate soil erosion in Miyun Country. It is clear from the results that, even if some uncertainties and inaccuracies are present, the USLE model can be efficiently applied at the watershed scale with the modest data requirements. Although the results of this study are considered acceptable, due to the limitation of USLE, spatial heterogeneity in the watershed, and use of empirical data, there are still uncertainties in the calculated value. In further studies, more attention should be paid to the accuracy of USLE-factors and data precision.

\section{ACKNOWLEDGMENT}

This work was supported by national natural science foundation (41271004) , Beijing nova program (2010b046).

\section{REFERENCES}

[1] Wischmeier W.H., Smith D.D., Rainfall energy and its relationship to soil loss. Trans Am.Geophys.Union, 39 (1958) 285 291.

[2] Renard K G, Foster G R, Weesies G A, et al, Predicting soil erosion by water: a guide to conservation planning with the Revised Universal Soil Loss Equation(RUSLE).,USDA Handbook,No.537.(1978)

[3] J.L. Huang, H.S. Hong, L.P. Zhang, et al., Study on predicting soil erosion in Jiulong River Watershed based on GIS and USLE, Journal of oil Water Conservation. (2004) 18(5):75-79

[4] K.L. Zhang, W.Y. Peng, H.L. Yang, China's soil corrosion resistance value and its estimation, ACTA PEDOLOGICA SINICA. (2007) 44(1):7-13. 
[5] B.Y. Liu, P.J. Shi, WEPP basin water erosion forecast model, Bulletin of Soil and Water Conservation. (1998) 8(5):7-13. 